\title{
Experiments in Form
}

\section{Creating Dance in the Early People's Republic}

As the excitement of 1949 died down, it became clear that China's newly founded dance field was facing serious challenges. Among these, one of the most urgent was a lack of trained performers to populate new dance productions. This problem became exceedingly clear in the two-hundred-person music and dance pageant Long Live the People's Victory, staged in the fall of 1949 to celebrate the Chinese People's Political Consultative Congress (Zhongguo renmin zhengzhi xieshang huiyi) and Founding Day (figure 7). ${ }^{1}$ Several experienced performers had been strategically cast to raise the show's artistic quality: Wang Yi, a virtuoso folk performer from Hebei, performed a solo in the opening "war drum dance" segment; a group of drummers was brought in from Ansai County in Shaanxi to perform in the "waist drum dance" portion; and Dai Ailian gave a modern dance solo during the climactic final scene showing the leading power of the working classes. ${ }^{2}$ Even these highlights, however, could not make up for the almost complete lack of training of most of the performers. Hu Sha (1927-2013), who codirected the production along with Dai Ailian, lamented the situation, writing, "most [of the performers] were students of only a few months, the majority of whom had not studied dance before, and their performance technique was still quite poor."3 Anyone who has attempted to stage a full-scale dance production, let alone a national pageant, by performers with only a few months of training can certainly sympathize with Hu's distress.

Not surprisingly, the problem of technical quality came up in some reviews of the performance, especially those by respected cultural figures responsible for guiding artistic development in the new society. Tian Han (1898-1968), a leading theater critic, dealt with the issue gently but clearly. While Long Live the People's Victory had taken the right approach and had served its immediate purpose, he argued, much 


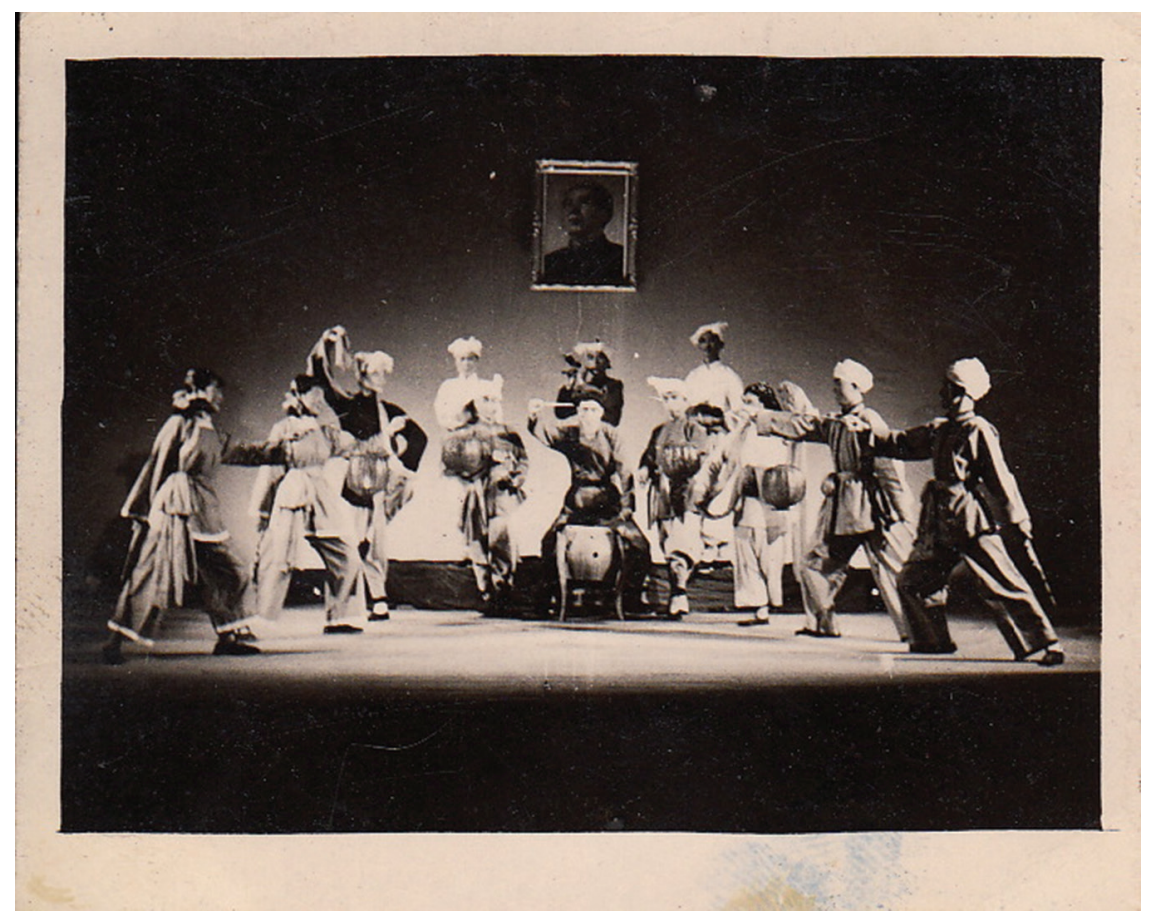

FIGURE 7. Long Live the People's Victory, 1949. Photographer unknown. Reproduced with permission from the private collection of Zhang Ke.

more work still needed to be done if this type of performance was to have lasting appeal in new China. "We have taken the correct path," Tian wrote, "but we need to keep going and find greater depth. Otherwise, this excitement will not last." 4 The main problem with Long Live the People's Victory, Tian argued, was the immaturity of its artistic form, which was especially problematic given the seriousness of the content the production addressed. Hu states that Long Live the People's Victory was supposed to embody four themes: "the people's democratic dictatorship, the leadership of the proletariat, taking workers and peasants as the foundation, and national unity."5 To express these lofty themes using unsophisticated artistic forms, Tian felt, was inappropriate. "The costumes, dancing, and other aspects of the artistic form are still not able to match the conceptual content," he concluded. ${ }^{6}$ Reflecting the moment's visionary zeitgeist, Tian was concerned less about the present than about the future. Although Long Live the People's Victory satisfied audiences now, he warned that its appeal would not endure. For revolutionary dance to move audiences in the future socialist society, it needed to rise to a higher artistic standard.

This search for a higher standard occupied professional dancers for the remainder of the decade, making the 1950 s the most exciting period of growth, 
experimentation, and innovation in Chinese dance history. For dancers like Dai Ailian, the period presented the special opportunity to build dance institutions from the ground up. However, to do so required not just developing new repertoires and teaching new students but also finding experienced dance artists to help. As Dai had pointed out in her 1946 lecture at the Chongqing Plenary, creating Chinese dance could not be done by one person alone; it required a team. ${ }^{7}$ Because dance talent was still scarce in the capital, this meant reaching out, beyond Beijing and even outside China. In a letter dated May 2, 1950, Dai wrote to her second cousin Sylvia, then in the United States, inviting her to help with dance work in Beijing:

My dear Sylvia: . . . For some time I have heard you say that you would like to return to China. ... . If this is still your desire, all I can say is come quickly. We need you very much here, and you will find good working conditions.... We need teachers, dancers and choreographers. ... Please write to me and let me know if you will come, and if you have any difficulties in coming, and in which way we may be able to help you. ${ }^{8}$

Sylvia accepted Dai's invitation, but not until the end of the 1950s, when it was already too late for her to significantly shape the direction of Chinese dance. ${ }^{9}$ In the meantime, Dai and her colleagues would find assistance from artists with transnational experience more nearby: Qemberxanim, the Uyghur dancer trained in Tashkent and Moscow, who was by the late 1940s leading a dance movement in Xinjiang, and Choe Seung-hui, the Korean dancer trained in Tokyo who had given a successful solo world tour and was by the late 1940s leading a dance movement in North Korea. As discussed further below, both women would visit Beijing several times in the early 1950s, both concretely impacting new developments in the Chinese dance field.

In many ways, the exuberance of the early 1950 s came from the fact that China's dance field-including most of its people, institutions, and dance forms-was extremely young. Wu Xiaobang, the most senior person focused on dance work as of 1949, was just forty-three, while Dai Ailian and Liang Lun were a mere thirtythree and twenty-eight, respectively. China's first national dance company-the Central Academy of Drama (Zhongyang xiju xueyuan, hereafter CAD) Dance Ensemble, led by Dai Ailian-was established in December of 1949 and initially comprised members between the ages of fourteen and twenty-six. ${ }^{10}$ In early 1950, a report compared CAD's three cultural work troupes-opera, spoken drama, and dance-concluding that the dance group was "the youngest ... [and] despite being a performance ensemble in name, is actually training-based." ${ }_{11}$ The fact that the majority of the ensemble's 129 members were still in the learning phase reportedly gave the ensemble a sense of newness and exploration. "The new Chinese dance still needs to be created," the report explained, "In the dance troupe, everything 
is still being explored and tested."12 As the language of this report makes clear, Chinese dance was still being imagined as something new and in a state of emergence. Much like the dancers who embodied it, Chinese dance was young, hopeful, and forward-looking. Its mature form did not yet exist. It needed to be created.

The relative lack of institutionalized knowledge and technical conventions allowed dancers in the 1950 s to engage in a high degree of formal innovation and broad-ranging aesthetic experiments. As in China's other artistic spheres, this was a period rife with debate and disagreement, as well as rushed creation that ended at times in brilliant success and at times in awkward failure. Most often, the truly tantalizing problems clustered around issues of form, not content. After all, as Dai and her followers argued-expressing both Mao's call for national forms and Dai's commitment to developing a new dance language on the basis of local performance practices-it was form that defined Chinese dance. As a result, questions of form motivated the vast majority of dance exploration during this period, when no one could say for certain what Chinese dance was, only that they knew they wanted to create it. Motivated by the call to serve and the need to produce results, sometimes with limited resources, dancers took risks and made do with what they had. It was in these thrilling times that Chinese dance emerged as a coherent artistic form, partly by plan but also by accident.

\section{EARLY ATTEMPTS: BRAVING WIND AND WAVES AND PEACE DOVE}

Two large-scale productions attracted the attention of China's dance field in 1950, one involving Liang Lun in Guangzhou and the other Dai Ailian in Beijing. The Guangzhou production premiered in July 1950 and was a six-act song and dance drama called Braving Wind and Waves to Liberate Hainan (Chengfengpolang jiefang Hainan), based on the military victory of the People's Liberation Army (PLA) on Hainan Island that April. ${ }^{13}$ It was created and performed by the South China Cultural Work Troupe (Huanan wengongtuan), with Liang Lun codirecting and serving on the collaborative choreography team with four colleagues. ${ }^{14}$ The Beijing production premiered formally in October 1950 and was a seven-act dance drama called Peace Dove (Heping ge), made to celebrate the international peace movement and the Stockholm Appeal, which had been signed earlier that year.15 It was written by Ouyang Yuqian, then director of CAD, and performed by the CAD Dance Ensemble. Dai starred in the production and also served as a member of the six-person choreography team. ${ }^{16}$ Braving Wind and Waves and Peace Dove had much in common: both were government-assigned projects dealing with current political events; both were created around the same time; and both involved leading choreographers with similar visions for the goals and principles of Chinese dance creation. Nevertheless, the final results of these two works could hardly have 
been more different, in terms of the dance techniques they employed and their overall aesthetic execution. These divergent productions thus demonstrate the range of possibilities that existed during this first year of the new nation's dance experiments.

Braving Wind and Waves told a triumphant story of the PLA crew that expelled Nationalist forces from Hainan, a tropical island on the southern coast of China, in one of the final military encounters of the Chinese Civil War. The story began with depictions of the suffering of the Hainan people under KMT rule (act 1), followed by the soldiers' training on land and in water (act 2), the soldiers' pact on the eve of battle (act 3), sailing across the sea with the help of local boat rowers (act 4), embarking on land and joining with other PLA forces (act 5), and celebrating with the island's inhabitants, including Li nationality communities (act 6). ${ }^{17}$ Audiences described the show as suspenseful and gripping: "The whole drama has so much tension it hardly gave one's nerves a chance to breathe" was one viewer's response..$^{18}$ Although the overall tone was heroic and celebratory, it also had variations in mood that lent it a sense of realism. Among the darker issues it explored were the soldiers' fear of death and their lack of experience with fighting on water. The scene in which the soldiers cross the sea on boats depicted them suffering seasickness, and a sense of tragedy accompanied the signing of a blood pact in which soldiers vowed to fight to the death. ${ }^{19}$ The production was created specifically to welcome the returning PLA soldiers on their way back from Hainan. Thus, its first audiences were the very people whose story the work narrated. ${ }^{20}$

In terms of performance form, Braving Wind and Waves was notable for its blending of diverse mediums and its use of techniques drawn from regional folk performance. In an article published in Dance News in 1951, Liang Lun described the formal structure as follows:

Initially, our plan was to use the dance drama form. However, in our troupe there were only a little over twenty comrades who had dance experience. The majority had experience in theater, music, and stage technology. Under these conditions, it would be difficult to realize the production purely through dance. But, using opera or spoken drama was also difficult to express this content. Also, we wanted to make use of the skills of the performers in each department. So, we decided to use a free form (ziyou xingshi) that made dance primary but added song and dialogue. Based on the content, we completely used dance to express the content of the prelude and the first and second scenes of act one. For acts two, three, and four we added speaking, clapper-talk (kuaiban), ${ }^{21}$ and singing. Because we aimed to create a sense of power, we also used a method of choral accompaniment. The sixth act then completely used dance. ${ }^{22}$

The dance movements used in the group choreography in Braving Wind and Waves were created through experiential research, known as "learning from life." This was an artistic method that Mao Zedong and CCP cultural leaders had widely promoted since the early 1940 s in Yanan, and it informed much dance creation in 


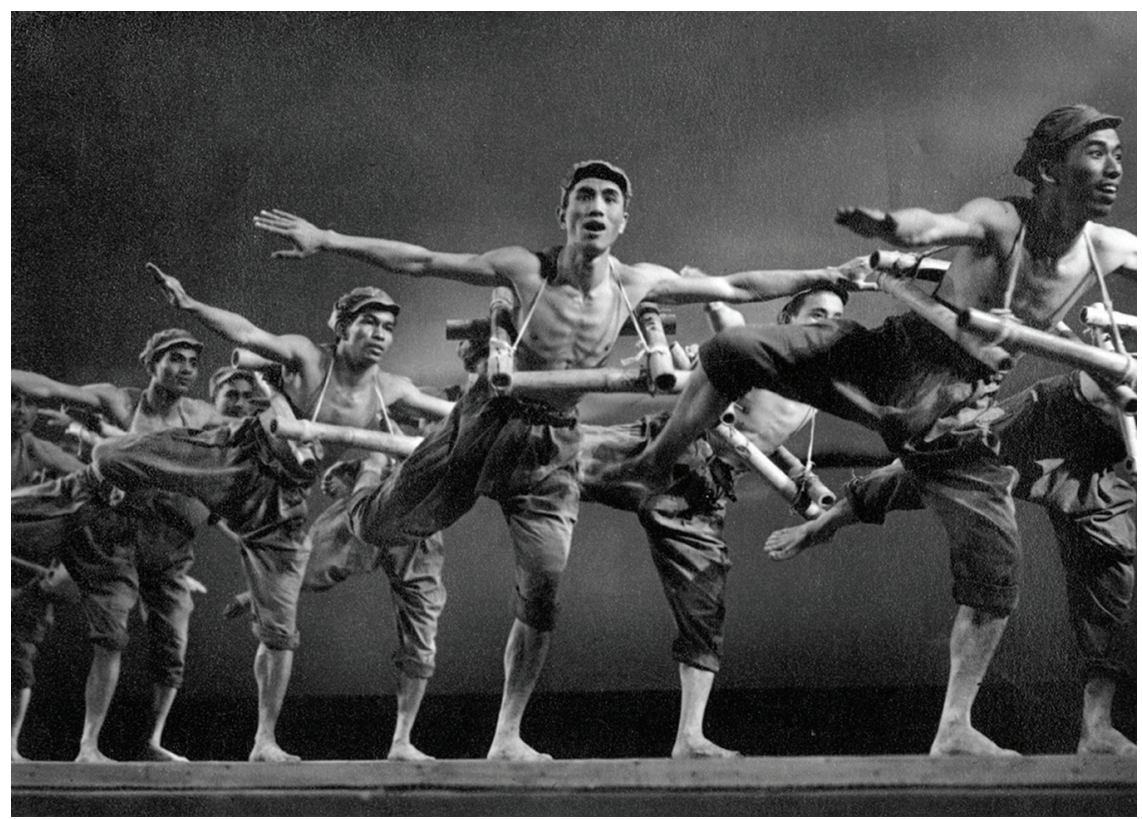

FIGURE 8. Braving Wind and Waves to Liberate Hainan. Published in Renmin huabao 1, no. 6 (December 1950): 37. Photographer unknown. Image provided by China Foto Bank.

China both during and after the socialist period. ${ }^{23}$ Describing this choreographic research process as it was carried out for Braving Wind and Waves, Liang wrote: "With help from the military, we were able to ride in some of the sailboats they had used. Practicing in the Pearl River, we had boat rowers teach us how to operate the rudder, raise and lower the sails, pull in the anchor, etc. Then, we invited people who had experienced war to tell us stories about training soldiers, crossing the ocean, and embarking on land." ${ }^{24}$ Extant stage photographs offer hints of the movements devised from this research: in one, a dancer grasps a rope and thrusts his weight into it, as if maneuvering the sails of a large boat; in another, male and female boat rowers look into the audience and lunge in unison, lifting oars over their heads with one hand and clenching their fists in front of their bodies with the other; in another, soldiers wearing makeshift bamboo life preservers balance on one leg, arms out, with the other leg kicking back and their mouths gulping air as if in midswim (figure 8). ${ }^{25}$

The music and stage design used in Braving Wind and Waves also showed formal experimentation and blending of performance styles. Musically, the production had an original score that included twenty-five songs in total. Following a common practice in performance works of the time, some songs drew themes from existing revolutionary music. For example, during the scene in which the 
soldiers signed their oath, the tune from "Without the CCP There Would Be No New China" was used. ${ }^{26}$ Other segments used hybridized compositions that sought to evoke native Hainan music. This occurred in the Li dance segment, which featured a rhythm inspired by Li nationality dance music, played on a Guangdong wooden xylophone accompanied by oboe, flute, clarinet, violin, and cello. ${ }^{27}$ The most sonically dominant component of the production's musical score was its percussion ensemble. According to musical directors Shi Mingxin (1929-2002) and Ming Zhi, "percussion accompanied the whole drama from beginning to end, and in the middle sometimes was used on its own." ${ }^{28}$ Although the string and wind components of the orchestra used Western instruments and modalities, and the choral music was composed in Western-style four-part harmony, the percussion ensemble was from Chinese opera. Shi and Ming described this component of the score as particularly effective because it used "native-style musical effects," with which audiences were "very familiar." ${ }^{29}$ It is unclear whether the specific percussion ensemble used was from Peking opera or Cantonese opera, but in either case it would have included gongs and cymbals, and, depending on the style, either a drum and clappers or woodblocks..$^{30}$ One can imagine the rapid "tap, tap, tap" of clappers or woodblocks, punctuated by the "tsah tsah TSANG" and crashing of the cymbals and gongs, all lending rhythm and suspense to the soldiers' dance movements, set against a surging choral and symphonic background. In terms of stage design, simple but realistic sets were used that resembled those of spoken drama or pageants. They included flags, a raised boat deck, boat sails, and a painted backdrop of sky. Costumes were also realistic and simple. They included military uniforms for soldiers, rustic tunics and loose pants for boat rowers, and embroidered jackets, skirts, and loincloths for the Li islanders. All of the dancers performed barefoot, and their makeup was minimal. ${ }^{31}$

The second production, Peace Dove, had a more abstract focus on the international peace movement that did not lend itself to the same type of realistic storytelling. Its structure was more symbolic, as demonstrated by the fact that the lead character is an anthropomorphized dove, played by Dai Ailian. The production contained seven acts organized around themes such as opposing US imperialism and financial oligarchy, opposing war and nuclear weapons, and promoting world peace. ${ }^{32}$ The story began with a group of doves called to disseminate peace at the beckoning of a red star (act 1), followed by a warmonger dressed as Uncle Sam who injures one of the doves (act 2), a worker who saves the injured dove (act 3), a crowd that is inspired by the doves and angered by the warmonger (act 4), dockworkers who refuse to transport US ammunition slated for Korea (act 5), the warmonger's flouted dream of world domination through financial manipulation and the atom bomb (act 6), and the peace dove's triumphant arrival in Beijing (act 7). ${ }^{33}$ As a historic achievement, Peace Dove was lauded as the PRC's first "large-scale dance drama." ${ }_{4}$ 
According to its writer, veteran theater expert and director of CAD Ouyang Yuqian, Peace Dove aimed to avoid reportage-like naturalistic mimes and gestures and instead present poetic tableaus that emphasized elemental emotions related to the central theme. ${ }^{35}$ In terms of setting, the work was unusual in that every act, with the exception of act 7 , took place in unspecified locations outside China. ${ }^{36}$ These settings, combined with the foreign symbol of the peace dove and the theme of the global antiwar movement, gave Peace Dove a strong aspiration toward internationalism. ${ }^{37}$

In terms of performance form, Peace Dove was notable in its adoption of classical and modernist European aesthetics. Structurally, it followed the eighteenth-century European model of the ballet d'action, or a story told completely through movement without words. Act 7, set in Tian'anmen Square in Beijing, used Chinese-style dance techniques drawn from New Yangge and Frontier Dance. ${ }^{38}$ The remainder of the choreography, however, used the movement conventions and techniques of ballet and Western modern dance. Chen Jinqing, who served as a member of the choreography team, described the choice to use these aesthetic modes as follows:

The rhythm of the dove is most suitably expressed through ballet technique. Therefore, the first and third acts mainly portray the doves, and these made ample use of ballet technique. In these sections, Dai Ailian's application of foreign technique was very successful. For the workers, masses, warmonger, etc. we used modern dance technique, because modern dance technique is relatively energetic and free. It is suited to expressing contemporary feelings and life. Using both techniques in a single dance drama was in accord with the needs of the script. At the same time, this type of expressive method was also an experiment. ${ }^{39}$

Stage photographs published at the time of the production demonstrate the prominence of ballet vocabulary in Peace Dove's choreography. Dai Ailian, who portrayed the lead dove, danced her role in pointe shoes, a technique specific to ballet, and her duet with the worker in act 2 employed standard ballet lifts such as the "fish dive." ${ }^{\circ}$ The choreography performed by the group of doves was also filled with ballet movement, including balletic port de bras, or arm lines, upward chest carriage, hip turnout, straight legs, and pointed feet (figure 9). ${ }^{41}$

European classical and modernist aesthetics were also evident in the music and costuming designs devised for Peace Dove. An original orchestral score was composed that consisted primarily of European string, wind, and brass instruments. ${ }^{42}$ At least one segment borrowed a tune from Chopin, and the overall score possessed what one critic called "a strong air of the Mozart era." ${ }^{43}$ Costumes combined conventions from Romantic ballets and early twentieth-century European-style Chinese spoken drama. The doves wore white bodices with chiffon butterfly-style sleeves, tutus, and ballet slippers, and on their heads were feathered crowns similar to those worn by the swan characters in Swan Lake. The workers were dressed in white collared shirts and overalls typical of proletarian characters in Chinese 


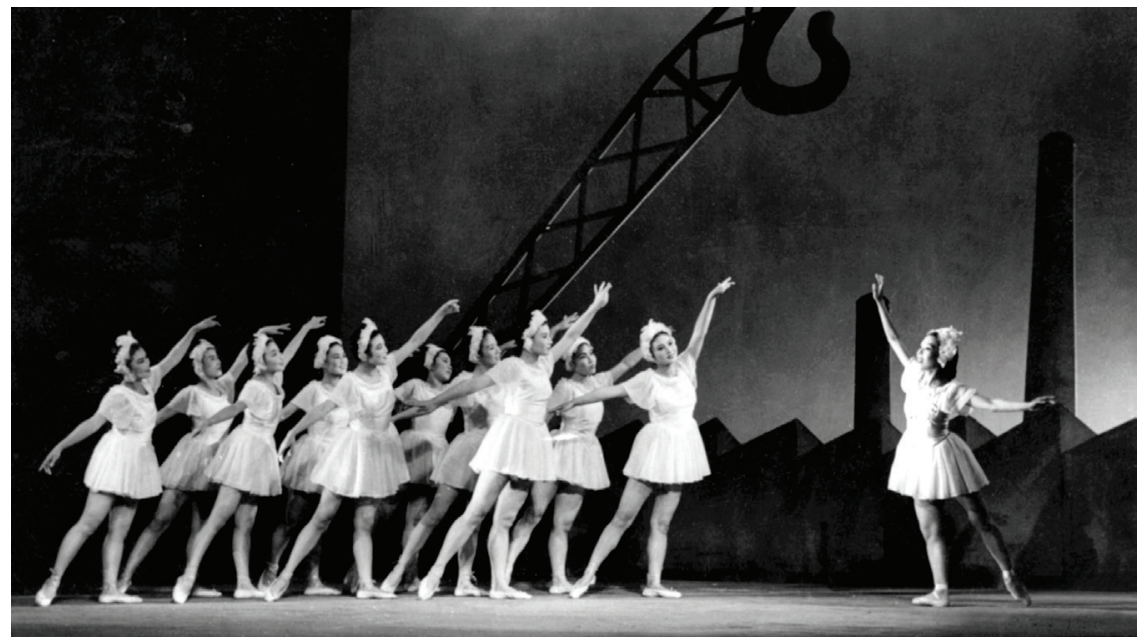

FIGURE 9. Dai Ailian and ensemble in Peace Dove. Published in Renmin huabao 1, no. 6 (December 1950): 38. Photographers: Wu Yinbo and Xia Yuqing. Image provided by China Foto Bank.

wartime political drama, while the warmongers wore tuxedos, top hats, and European-style ball gowns like those used in 1920s- and 1930s-era Chinese spoken drama productions portraying stories set in Europe and the United States. ${ }^{44}$

Stage design was one of the most experimental components of Peace Dove. Extant photographs show the use of elaborate sets comprising a combination of industrial landscapes, abstract symbols, and modernist sculpture. In act 1, a red star beacon rises above stage boards cut to resemble ocean waves. In act 2, an empty field is planted with giant swastikas and crosses, and a giant coin stamped with a dollar sign fills one side of the stage. Acts 3 and 4 take place under a towering mechanical construction crane, and the background is lined with smokestacks and cube-like structures resembling a skyline of urban tenements. In act 5 the stage is transformed into a dock with large boats and stacks of shipping crates. Act 6, portraying the warmonger's dream, returns to symbolist abstraction with a towering stack of coins, an atom bomb on wheels with a glamorous woman sitting atop, and a trapezoidal US flag mounted with a model warplane. Finally, act 7 has a painted backdrop of Tiananmen Square topped with floating images of Mao Zedong and Joseph Stalin shaking hands amid flying doves.

\section{FINDING CONSENSUS: RECEPTION AND DEBATES \\ OVER DANCE FORM}

Given the vast differences in approach between Braving Wind and Waves and Peace Dove, it is not surprising that the critical responses were also quite different. 
Overall, Braving Wind and Waves received positive reviews and was held up as an example for future dance creation to follow. Meanwhile, the responses to Peace Dove were so harsh that by January of 1952, the renowned poet Guang Weiran (1913-2002), who served as head of education at CAD and at first defended Peace Dove against critics, published a self-criticism in People's Daily in which he accepted culpability and acknowledged the work as a failure. ${ }^{45}$ For years, references to Peace Dove appeared as examples of what not to do when creating Chinese dance drama, in particular with regard to the question of using ballet movement form. ${ }^{46}$ Thus, these two productions not only evince the wide range of variation in early $1950 \mathrm{~s}$ dance creation but also show how a consensus gradually formed regarding the parameters of Chinese dance as a new artistic medium in the early PRC.

In their responses to Braving Wind and Waves, critics were impressed by the extreme ingenuity displayed by members of the creative team, their willingness to draw on diverse performance forms, and their attention to local elements. Initial reviews in national newspapers marveled at how quickly the production was created - under twenty days from conception to premiere - and described it as very effective at devising new mediums to portray its selected themes. One critic wrote, "This drama uses all kinds of new dance forms and its imagery portrays the great struggle of the PLA ... all very successfully." ${ }^{47}$ Photographs of the work received an entire spread in the national magazine China Pictorial (Renmin huabao), significant recognition for a regional production. ${ }^{48}$ Additionally, local reception was so positive that the Guangzhou Municipal Committee and the Guangdong Province People's Government Bureau of Education and Culture each awarded subventions of 10 million yuan to help develop the work into a lasting repertory piece..$^{49}$ When an international representative team from the World Festival of Youth and Students (Shijie qingnian lianhuanjie) visited Guangzhou, Braving Wind and Waves was selected to be performed for the team, and the show had an additional local run of over thirty performances, followed by symposia to discuss its creative process. $^{50}$ Finally, a group from the Ministry of Culture was sent to Guangzhou to review the work, and they selected it to be performed in Beijing the following year as part of a national festival..$^{1}$

When Braving Wind and Waves was shown in the Beijing festival the following year, it continued to receive positive reviews from Beijing-based dance critics. In his 1951 review of nationwide dance creation over the previous year, China Dancers Association vice president Wu Xiaobang singled out Braving Wind and Waves for special praise, calling it "something that dance workers around the country should study". ${ }^{2}$ Following the now state-compelled endorsement of local aesthetics, Wu commended the work's creators for adapting elements from Chinese opera and from other styles of local performance-a technique he called "creating as appropriate to the place" - and for boldly pushing the boundaries of existing forms. "Dance workers need to create using a range of forms, not staying limited 
to the tried methods," he concluded. ${ }^{53}$ A review of the national festival argued that the works it featured, including Braving Wind and Waves, showed some roughness and lack of polish but concluded that "in terms of the direction of creation and development of new dance art, we can confirm that it is correct." ${ }^{54}$ Finally, Hu Sha wrote that while he would like to have seen even more adaptation of native performance styles in the production, he nevertheless still felt that its creative approach was in the right direction. ${ }^{55}$

Whereas critics viewed the blending of artistic mediums and adaptation of local performance in Braving Wind and Waves as creative, forward-looking, and appropriate to the tastes of contemporary audiences, they regarded Peace Dove's adoption of European classical and modernist aesthetics as morally questionable, unsuited to contemporary audiences, and artistically old-fashioned. Concerns about the work's aesthetic choices apparently began at the level of the ensemble members even before the work went into production. Peng Song, who served on Peace Dove's choreography committee and also performed the role of Uncle Sam/ warmonger, recalled that when ensemble members were told of the plans, "Some people questioned whether copying the expressive methods of ballet and lacking native dance style was appropriate." ${ }^{56}$ Guang Weiran had apparently made a special visit to meet with the ensemble members to subdue their dissent. According to Peng, Guang instructed ensemble members to respect the views of the work's writer and CAD director, Ouyang Yuqian, who was a very respected figure in the cultural community and had great experience with drama creation. ${ }^{57}$

When Peace Dove had its initial preview showings, serious concerns were expressed again, this time from audiences. The story is referenced in many contemporary accounts and is widely recognized as a key turning point in the history of both Chinese dance and ballet in China..$^{58}$ Peng tells the story as follows:

Peace Dove had two performance periods. The first one was in September, for the opening of the second World Peace Congress, and it took place in Beijing Theater and the Xinhua News Agency Auditorium. The response was good, largely affirming. However, after seeing it, some of the transferred worker-peasant students ${ }^{59}$ from CAD cried out in alarm: 'A stage filled with thighs; workers, peasants, and soldiers despise. ${ }^{\prime \circ}$ Many ridiculed the production for 'corrupting public morals.' In response to this, comrade Guang Weiran defended Peace Dove by saying, 'We need to work hard so that in a few decades from now workers, peasants, and soldiers will be able to stomach looking at thighs.' When the critics heard this, they went into an uproar. For this reason, after a few shows Peace Dove unfortunately stopped performing. Only act seven 'Peace dove flies to Beijing' was performed at a few galas. ${ }^{61}$

The controversy over Peace Dove's aesthetic form revolved primarily around its use of ballet aesthetics, including the technical focus on leg work and the use of short tutus that highlight this component of the movement and the female dancers' bodies. During China's colonial modern period, the exposure of women's 
thighs had become associated with Westernization and the moral corruption of capitalism. In cities with large foreign populations and semicolonial governance like Shanghai, "thigh dancing" (datui wu) was shorthand for dance styles such as cabaret, burlesque, and striptease, all of which were seen as vulgar Western imports. ${ }^{62}$ Thus, by calling Peace Dove "a stage filled with thighs," the workerpeasant students were locating ballet as part of the cultural legacy of Western concert dance, understood as a form of popular stage dance associated with commercial culture and colonialism in the Chinese historical context. From this perspective, they argued, ballet could not be considered appropriate for a dance form meant to embody revolutionary ideals. In his response, Guang Weiran attempted to reclaim ballet from this interpretation by arguing that it was similar to spoken drama, a Western form that had nevertheless been adapted to Chinese needs. "We just have to think of how the foreign spoken drama form gained practical connection to Chinese people's lives and became accepted by the people, quickly becoming one of our national forms," Guang argued. ${ }^{63}$ Many found Guang's claim unconvincing, however, and new criticisms of Peace Dove continued to pile up.

The most damning critique came from Zhong Dianfei, a budding film critic who at the time worked in the Ministry of Culture. In late 1950, Zhong published a review of Peace Dove in Literary Gazette (Wenyi bao), China's leading literary and arts journal. Like the transferred worker-peasant students, Zhong argued that Peace Dove was insufficiently revolutionary. However, rather than taking the perspective that it was morally corrupt and excessively Western, Zhong instead argued that it was simply old-fashioned and artistically uninspired. Zhong hung much of his argument on the fact of Ouyang Yuqian's advanced age-introducing the latter as "an old man already past sixty" - and suggested that the problems with Peace Dove resulted largely from Ouyang's being out of touch with the tastes of contemporary audiences. ${ }^{64}$ Turning Guang Weiran's claim on its head, Zhang argued that the problem was not that contemporary audiences needed time to rise to the level of art depicted in Peace Dove, but, rather, that they were already far beyond it. "The intended audience of today's art is already revolutionary," Zhong argued, "and may have a great deal of experience with revolutionary practice. . . . So, their expectations for art are relatively high." ${ }^{65}$ Zhong regarded the plot and expressive modes employed in Peace Dove as superficial, ineffective, and tiringly out of date. Although he did not agree with the students, Zhong still condemned the use of European dance technique in Peace Dove, on the basis that it was too traditional. "Although ballet is already accepted and has been absorbed in the USSR, it still does not possess a mass quality . . . all traditional artistic forms have limits," Zhong concluded. ${ }^{66}$ Thus, rather than making Peace Dove revolutionary, the use of ballet, in Zhong's estimation, gave it a retrograde quality.

The idea that using European classical forms made Peace Dove seem stuck in the past was a common complaint among contemporary critics. During a 
symposium held at the Central Music School, the composer Su Xia made a similar argument about Peace Dove's musical composition. Su stated, "The most unharmonious aspect of Peace Dove's score is that on the stage we see typical phenomena of the year 1950, while the music is still in the style of around $1770 .{ }^{\prime 67}$ Like Zhong, $\mathrm{Su}$ found the use of European classicism not just mismatched with the content but also unlikely to appeal to China's new audiences, who Su argued had a strong desire for innovation. The problem, therefore, was not just that the music was of a different time period but that it lacked newness: "Overall, the music is too imitative, and many phrases feel quite familiar," Su chided. From both Zhong's and Su's perspectives, what was needed to attract Chinese audiences and reflect the revolutionary society was innovation, not imitation.

Braving Wind and Waves and Peace Dove gave audiences much to think about in terms of what constituted truly revolutionary modes of artistic expression, and they also generated interest in the new creative medium of "dance drama" (wuju) among a wider portion of China's cultural and artistic community. By the end of 1950, not just dancers and playwrights but also composers, poets, film critics, and worker-peasant students were all chiming in about the future of Chinese dance form. At the same time, neither Braving Wind and Waves nor Peace Dove was able to resolve this problem, since neither offered a concrete model for movement conventions for Chinese dance. Although recognized as a positive example, the success of Braving Wind and Waves lay in its multimedia composition, realistic storytelling, and adaptation of local music and oral performance, not its innovations in dance form. Thus, when categorizing works in the 1951 dance festival, Hu Sha labeled Braving Wind and Waves as a production that contributed to the problem of how to reflect the content of mass struggle but not the problem of how to use local elements and develop national forms in dance movement. ${ }^{68}$ At the same time, although Peace Dove had attempted to innovate in dance form by using ballet and modern dance, it had not been successful. That is, audiences and critics had not accepted ballet and modern dance as legitimate mediums for expressing Chinese revolutionary culture. This left Chinese dancers once again searching for new formal possibilities.

The uncertainties about dance form manifested in these critical debates over Braving Wind and Waves and Peace Dove reflect larger questions regarding the relationship between form and content in socialist performance that traced back to the "national forms" debates of the Yan'an period. Specifically, critics and choreographers alike were still trying to determine what role, if any, Western dance forms should play in the making of China's new national forms. At the same time, the issue of how folk and vernacular forms could contribute to these new forms also continued to be a persistent problem. As had happened with Dais Frontier Dance repertoires during the 1940s, minority forms and xiqu once again appeared as solutions to the problem. At the very same moment that critics were casting 
their votes on Braving Wind and Waves and Peace Dove, two new possibilities presented themselves to the Beijing dance community that made possible a shift in this direction. One of these came from Xinjiang and other parts of the former "frontier." The other came from an artist in North Korea who was enthralled with the creative possibilities of xiqu.

\section{NEW VOICES: MINORITY DANCE AND MINORITY \\ DANCERS}

The dances of non-Han groups had played an important role in early visions of Chinese dance and in the 1949 All-China Literature and Arts Worker Representative Congress. However, once the early proponents of these forms, most of whom were of Han ethnicity, moved back to Han-dominated urban centers on the east coast, they lost opportunities to conduct fieldwork and collaborate with minority artists, making it difficult to create new works using these dance styles. An attempt to represent minority groups on stage had occurred in the 1949 pageant Long Live the People's Victory when, in the final two scenes, dancers dressed as Han, Hui, Miao, Mongol, Taiwanese, Tibetan, and Yi performed together along with dancers dressed as workers, peasants, soldiers, students, and merchants, in an effort to reflect the various social groups thought to form the revolutionary movement. ${ }^{69}$ Although the choreographers of this scene had significant experience with minority dance-they included Peng Song, Ge Min, and Ye Ning, all of whom had been involved in pre-1949 Frontier Dance-the fact that the performers were almost all Han students with little dance training and almost no exposure to the culture of the ethnic groups being performed meant that little of the actual formal qualities of minority dance were conveyed. Tian Han's criticism of the formal inadequacy of Long Live the People's Victory cited above had noted this scene as particularly problematic. In his words, it appeared to "lack any true sense" of the minority dances that were meant to be portrayed..$^{\circ}$ By the spring of 1950, when this group, now the CAD Dance Ensemble, staged its second major production, The Great Yangge of Building the Motherland, portrayals of minorities had dropped out of the choreography. ${ }^{71}$

Just as minority dance seemed to be disappearing from Beijing's dance stages, however, groups of non-Han dancers from border regions-now called "nationality cultural work troupes" (minzu wengongtuan)_arrived in Beijing to give their own public performances. In October of 1950, just after Peace Dove made its initial appearance in theaters, the first large-scale tour of minority music and dance performed by minority artists was held in Beijing to celebrate China's first National Day. ${ }^{72}$ The tour featured 219 performers hailing from four major regions: the Southwest, ${ }^{73}$ Xinjiang, Inner Mongolia, and Yanbian. ${ }^{74}$ Among the ethnic groups represented were Kazakh, Korean, Manchu, Miao, Tibetan, Uyghur, Uzbek, and 


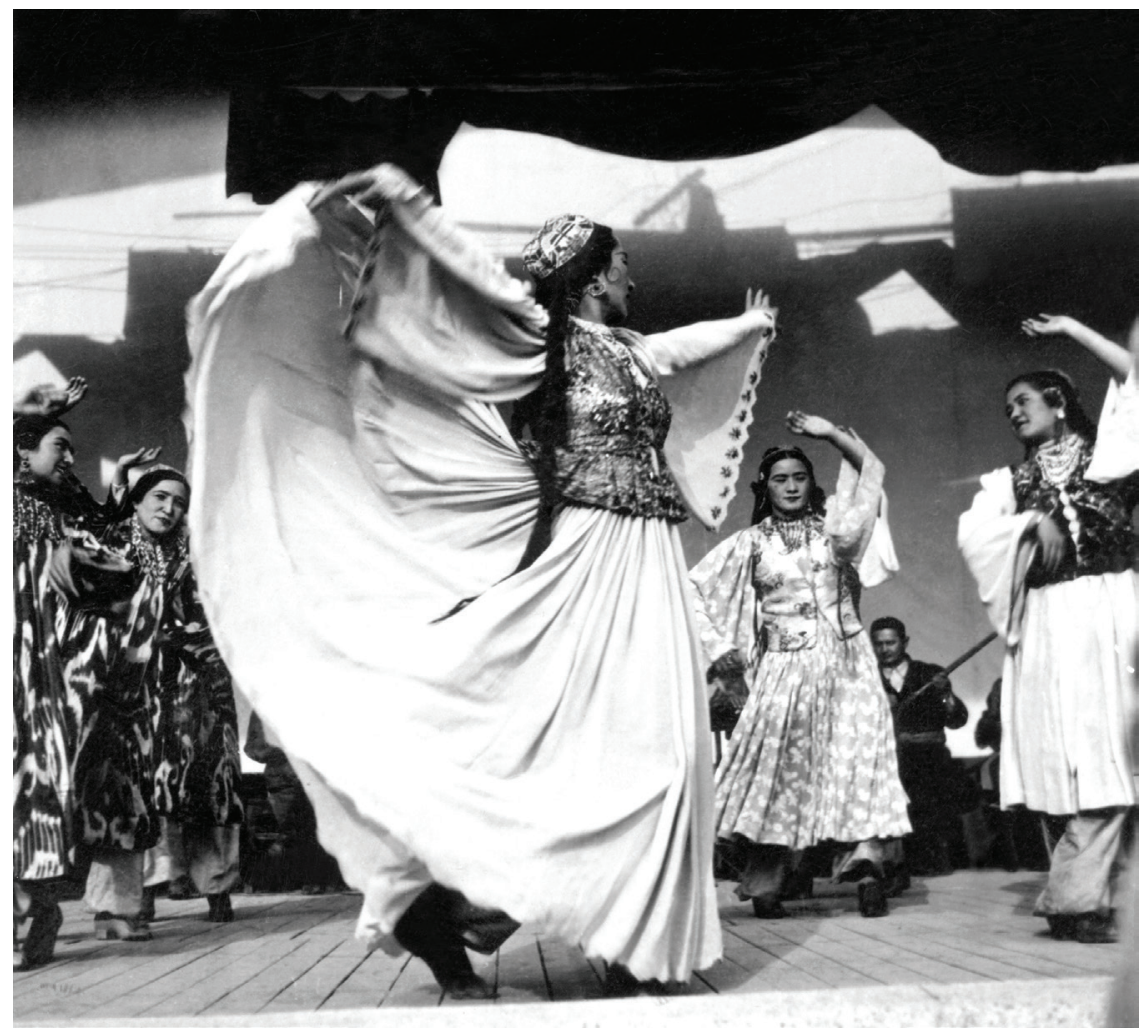

FIGURE 10. Qemberxanim and ensemble on Northwest Nationality Cultural Work Troupe Beijing tour. Published in Renmin huabao 1, no. 5 (November 1950): 37. Photographers: Chen Zhengqing et al. Image provided by China Foto Bank.

Yi, among others. The star of the tour was Qemberxanim, the Uyghur dancer from Kashgar who had returned to Xinjiang after studying dance in Uzbekistan and Moscow and gave a national tour in 1947 (figure 10). ${ }^{75}$ These dancers and musicians presented a joint four-and-a-half-hour song and dance gala that featured a wide range of artistic styles and genres-from Central Asian Muqam orchestra to Tibetan xianzi dance. ${ }^{76}$ After premiering at the gala for state leaders and minority representatives at the official minority gift-giving ceremony held on October 3, they gave seventeen additional shows in Beijing and Tianjin, with an estimated total live audience of 150,000. In addition, they participated in numerous banquets and social engagements and took part in artistic exchange and joint performances with local professional performance ensembles. ${ }^{77}$

A documentary film titled Songs of Tengri Tagh (Tianshan zhi ge), directed by He Feiguang (1913-1997), offers a rare glimpse into the dances of Qemberxanim. ${ }^{78}$ Shot in Shanghai during the Xinjiang Youth Ensemble tour of 1947-48, the film 


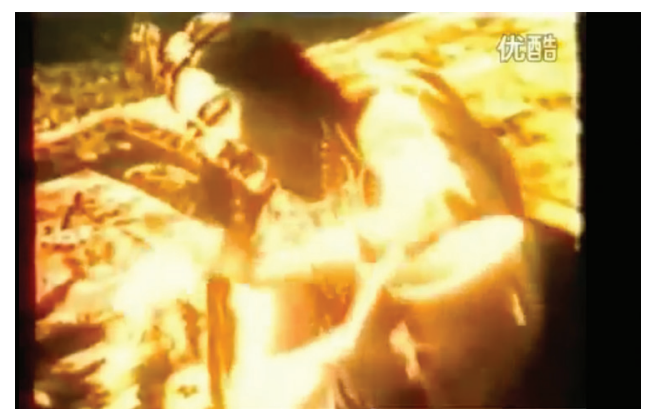

VIDEO 3. Qemberxanim and ensemble in "Plate Dance," from Songs of Tengri Tagh. Northwest Film Corporation and Central Film Studio, 1948.

To watch this video, scan the QR code with your mobile device or visit DOI: https://doi.org/10.1525/luminos.58.3

recorded music and dance items from the tour, including Qemberxanim performing one of her signature pieces, "Plate Dance" (Panzi wu) (video 3). ${ }^{79}$ Taken during an outdoor performance, the yellowed film shows Qemberxanim dancing solo while seven seated musicians offer live accompaniment on an ensemble of Central Asian percussion and string instruments. Bell-like gossamer sleeves hang down from Qemberxanim's arms, and on her head sits a beaded hat topped with feathers, below which waist-length black braids hang down and swing along her back. She holds a plate and a pair of chopsticks in each hand and clinks them like castanets, framing her face with her arms, as she circles the space in floating walks and spins. Eventually, she approaches the audience and lowers to her knees, dipping into a deep backbend. Then, as she is rising back up, she crosses her arms in front of her chest and performs a barely visible side-to-side head shift now iconic of female Uyghur-style dance. A close-up shot shows a confident smile filling her face as she glances sideways toward her audience. It is a dance filled with charisma and subtlety, and the plates and chopsticks make it reminiscent of a banquet performance.

The 1950 minority tour came at a time when members of Beijing's cultural scene were particularly concerned about the future of Chinese dance, and the mature performances of experienced dancers like Qemberxanim offered what many saw as a possible solution to their problems. Conveying the urgency many in the dance field felt at the time, Chen Jinqing, then vice director of the CAD Dance Ensemble, wrote in September, just before the minority tour, that "some are even questioning whether dance is a viable artistic form in China." ${ }^{80}$ Part of this concern had to do with a growing malaise toward New Yangge among urban communities, due in part to the disconnect between urban and rural culture and in part to the fact that yangge had been heavily simplified in the New Yangge movement in order to make it more quickly learnable and accessible. As Chang-tai Hung suggests, the boredom urban audiences developed toward New Yangge may explain why 
the creators of Peace Dove turned to ballet and modern dance in an attempt to innovate and find new forms. ${ }^{81}$ When this also failed to produce positive results, however, Beijing's dance community fell into a somewhat desperate state; the nationality tour offered the community tremendous new hope. Zhong Dianfei, in his dismal review of Peace Dove, offered an aside on the minority tour that implied he saw it as a more viable path for the future of Chinese dance than copying ballet and European aesthetics. "There are still many problems facing the development of Chinese national dance. ... The recent performances of northwest, southwest, Yanbian, and Mongolian nationality cultural work troupes in Beijing has given us much inspiration in this regard." ${ }^{2}$ Zhong compared what he saw as the new, and thus formally exciting, dance styles presented in the minority tour with the familiar, and therefore less interesting, forms used in Peace Dove: "if Ouyang had only not chosen such an average expressive medium, [Peace Dove] might have [like the tour] also provided inspiration." ${ }^{83}$ Other leading critics also responded positively to the tour. In his review of a work by Jia Zuoguang performed by the Mongolian dance ensemble, $\mathrm{Wu}$ Xiaobang suggested that it be studied as an alternative to New Yangge dance as, in his words, it was "more suited to the expression of contemporary life." ${ }^{44}$ Other critics from outside the dance community claimed to be moved by the performances on the tour and to have thereby gained a new interest in dance art. $^{85}$

Following the minority tour, the central government launched an effort to recruit more minority dance artists into professional positions, and new schools and ensembles were established that were specifically dedicated to training minority dancers and researching and teaching non-Han dance forms. In November of 1950, immediately after the tour, Qemberxanim traveled directly from Beijing to Xi'an, where she was recruited to help oversee plans for the incorporation of minority arts courses into the new Northwest Art Academy (Xibei yishu xueyuan) ${ }^{86}$ In 1951 Qemberxanim was appointed founding chair of the academy's Department of Minority Nationality Arts (Shaoshu minzu yishu xi), which became the PRC's first state-sponsored professional program dedicated to training performing artists from minority ethnic backgrounds. ${ }^{87}$ Under Qemberxanim's leadership, the program recruited 150 students from eleven different nationalities during its first year, including folk artists, elementary school teachers, students, and government functionaries. ${ }^{88}$ The department offered two areas of study: music and dance. Between 1951 and 1953, the dance program focused on what Qemberxanim described as "folk dances and classical works of northwest nationalities, such as Uyghur 'Hand Drum Dance, 'Dolan Group Dance,' 'Plate Dance, 'Russian Folk Group Dance,' Kazakh 'Spinning Wool Dance' and 'Moon Moon, etc." ${ }^{89}$ In order to systematize the instruction of basic skills for these dance styles, Qemberxanim developed her own teaching curricula that broke down movements according to seven categories: salutations, head movements, waist movements, steps, arm and hand movements, turns, and squats or pliés..$^{\circ}$ These curricula later 
served as the foundation for similar courses in minority dance taught at the Beijing Dance School, whose instructors were personally trained by Qemberxanim. ${ }^{91}$ In addition to coursework, students in the department participated in frequent performances and also conducted organized field research trips..$^{92}$ The graduates of this program went on to become prominent leaders in arts institutions specializing in minority nationality performance across the northwest region..$^{93}$

While Qemberxanim was leading the development of minority dance in the northwest, a national-level institution specializing in minority dance was also established in Beijing. The Central Academy of Nationalities (Zhongyang minzu xueyuan, hereafter CAN) Cultural Work Troupe, established on September 1, 1952, with Wu Xiaobang initially appointed as its director, became the PRC's second national-level dance ensemble, after the ensemble Dai Ailian led at CAD. ${ }^{44}$ These two ensembles were China's most important professional dance companies during the early 1950s, with the CAD ensemble ultimately specializing in Han folk dance and the CAN ensemble in dances of minority nationalities. ${ }^{95}$ Like Qemberxanim's program, the CAN group focused on recruiting and training performers from minority backgrounds-by the time of its ten-year anniversary, minority artists made up an estimated 60 percent of its total membership. ${ }^{96}$ To maintain a connection with minority communities outside the capital, the CAN ensemble made regular trips to border regions to carry out study and exchange. In September of 1952, for example, Wu led over 140 members on a research and study trip to Xian, where they performed with Qemberxanim's program at the Northwest Art Academy, before continuing on to Chongqing and other areas across the southwest. ${ }^{77}$ Photographs of the ensemble featured in China Pictorial in 1952 showed dancers from the troupe performing a wide variety of minority nationality dances, including Yi, Mongol, Yao, Gaoshan, Tibetan, Uyghur, Li, Yanbian (Korean), and Miao. ${ }^{98}$ Members of the ensemble also frequently represented China on tours abroad, as discussed in the next chapter. By recruiting and training new dancers and creating new choreography, the CAN ensemble constituted a dedicated center for minority-focused dance activities, ensuring that non-Han dance and dancers retained visibility and influence within China's broader professional dance scene.

\section{LEARNING FROM XIQU: THE BIRTH OF CHINESE CLASSICAL DANCE}

The last major experiment of this period in the Chinese dance field also took off at the end of 1950, though because of yet a different set of occurrences. At the same time that Peace Dove and the minority tour performances were going on in Beijing, the PRC was entering its first major military engagement with a foreign power-against the United States in the Korean War. Apart from making national unity an increasingly important theme in political and cultural discourse, this also 
had the effect of encouraging cooperation and exchange between the PRC and North Korea, which included activities in the dance field. It was in this context that Choe Seung-hui, a world-renowned Korean dancer, became intimately involved in shaping the future of Chinese dance. In particular, Choe led the project to create a new Chinese dance vocabulary based on the movement conventions of xiqu, especially those of Peking opera and Kunqu. This work resulted in the dance style that became known as Chinese classical dance.

$\mathrm{Xiqu}$ is a synthetic art form that traditionally combines four main elements, known as chang, nian, zuo, da (singing, speaking, moving, and acrobatic fighting). Because two of these four main elements deal with bodily movement, dance is considered to be a fundamental part of xiqu performance. Dance in xiqu can range from barely perceptible postural movements, gestures, and hand, head, and facial expressions to complex acrobatic routines that incorporate flips, spins, kicks, and other displays of physical virtuosity. Manipulation of stage properties such as fans, sleeves, swords, and spears is also an essential component of xiqu movement practice. Additionally, movement technique in xiqu typically accords with the social identity of the character being performed, meaning that xiqu movement is encoded with cultural messaging about age, class, gender, ethnicity, morality, and profession. ${ }^{99}$ During the early twentieth century, many Chinese artists experimented with the creation of modern dance choreography based on xiqu movement. As discussed in the introduction, Peking opera performer Mei Lanfang and his collaborator Qi Rushan were among those who explored such possibilities, and their work helped lay the foundation upon which Choe built.

Choe Seung-hui is one of the most influential figures in the history of twentieth-century East Asian dance. Because of her move to North Korea in 1946 and subsequent purging by the North Korean regime around 1969, however, research on Choe was banned in both South and North Korea until the late 1980s, and scholarship on her in English was consequently also limited. Since the 1990s, there has been an explosion of new Anglophone scholarship on Choe's career, particularly her 1938-40 world tour and her role as a colonial subject in Japan and Japanese-occupied Korea during the 1930 and early 1940 s. $^{100}$ One topic that has not received much attention, though, is the latter portion of her career, during which she led the development of new socialist dance pedagogical systems, stage repertoires, and choreographic theories in North Korea and China. ${ }^{101}$ Choe's activities in China occurred in two periods that represent two very different political and social contexts: the first was from 1941 to 1946 in the context of Japanese occupation and the War of Resistance against Japan and its aftermath; the second was from 1949 to 1952 in the context of China's socialist nation building, PRC-North Korean socialist cultural exchange, and the Korean War. In the Chinese-language dance scholarship produced in China, the activities in which Choe engaged during both of these periods are now seen as foundational to the history of Chinese dance, particularly 
to the early development of Chinese classical dance and Chinese Korean dance. ${ }^{102}$ Because Choe worked in so many different cultural, geographic, and political contexts throughout her life, her work changed over time and took on new meanings in different places and times. ${ }^{103}$

Choe Seung-hui was born in 1911 into a declining yangban family in Seoul during the Japanese colonial rule of Chōsen (Korea), which lasted from 1910 to 1945. In 1926 Choe moved to Tokyo to study with Japanese dancer Ishii Baku (18861962), a leading figure in Japan's modern dance movement whose company Choe had seen perform in Seoul earlier that year. Ishii had begun his own dance career in 1912 studying with Italian ballet master Giovanni Vittorio Rossi at the Imperial Theater in Tokyo, and in 1915 he had left the theater to pursue his own dance style. ${ }^{104}$ Starting in 1915, Ishii engaged in modernist collaborations with figures such as the composer Yamada Kosaku, who had been exposed to early modern dance while studying abroad in Europe, and around 1922-24 Ishii himself went abroad, visiting Berlin, London, and New York. ${ }^{105}$ Choe rose to fame initially as a dancer in Ishii's Tokyo-based company, where she performed an eclectic mix of dance styles and gained a strong foundation in ballet and Western modern dance. In 1929 Choe returned to Seoul to establish her own dance studio, which she ran for about three years before rejoining Ishii in Tokyo. The year 1934 marked a turning point for Choe: she debuted in Tokyo as a solo dancer and presented a large body of new Korean-themed works, which became the basis for her shinmuyong repertoire. ${ }^{106}$ Over the next few years, Choe rose to become one of the most famous cultural figures in the Japanese Empire, known primarily as a dancer but also as a model, film star, and singer. ${ }^{107}$ In late 1937 , Choe embarked on a world tour that lasted until 1940. During this time, she performed on three continents, visiting the United States, the Netherlands, France, Italy, Germany, Belgium, Brazil, Argentina, Uruguay, Chile, Peru, Colombia, and Mexico. ${ }^{108}$ It was soon after this trip that she began her work in China.

Choe first traveled to China in 1941, the same year that Dai Ailian arrived and just one year prior to Qemberxanim's return. The reason for Choe's visit was different from those of the other two, however, since she was sent as a representative of the Japanese Empire and performed in part for the entertainment of Japanese soldiers. ${ }^{109}$ Between 1941 and 1943, Choe performed three tours to Japanese-occupied areas of China and Manchukuo, a Japan-controlled puppet state set up in 1932 in what was previously part of northeast China. Among the cities Choe visited on these tours were Beijing (Beiping), Tianjin, Wushun, Shenyang (Fengtian), Dalian, Jilin, Changchun (Xinjing), Harbin, Qiqihar, Bei'an, Jiamusi, Mudanjiang, Tumen, Nanjing, and Shanghai. ${ }^{10}$ By this time, Choe's dances had expanded beyond her earlier Korean-themed shinmuyong repertoires to include additional works on Japanese, Chinese, Indian, and Siamese themes. ${ }^{111}$ In 1943 Choe sought training from Mei Lanfang in Shanghai and proposed the idea of creating a new dance style 
by studying and adapting elements of xiqu performance, specifically Peking opera and Kunqu. ${ }^{112}$ In 1944, Choe moved to Beiping and set up the Oriental Dance Research Institute (Dongfang wudao yanjiusuo), with support from Mei and other renowned xiqu actors. ${ }^{113}$

Initially, Choe's interest in Chinese dance likely came from a political need to respond to the Japanese imperial regime's cultural policies of pan-Asianism and the ideology of the Greater East Asian Co-Prosperity Sphere. During the early 1940s, when this policy was being implemented, Choe experienced pressure to perform dances reflecting not just Korea but the entire Japanese imperial domain. ${ }^{114}$ Choe's relationship to her Chinese colleagues was complex, however. According to Faye Kleeman, Choe "was particularly impressed by Mei [Lanfang]'s resistance to performing for the collaborating regime of Wang Jingwei," and Choe described her own move to Beiping in 1944 as "a form of 'exile." "115 Following the end of the Pacific War in 1945, Choe stayed on in Beijing for several months. Facing unwelcoming political climates in both Japan and South Korea, in 1946 she moved to Pyongyang, which would soon be the capital of North Korea ${ }^{116}$ Choe received a warm welcome from the North Korean government, and she performed extensively, in addition to running Pyongyang's first dance school. ${ }^{117}$ Following the establishment of the PRC in 1949, Choe's company was invited to Beijing and gave a series of high-profile shows attended by cultural leaders. ${ }^{118}$ This marked the beginning of a new period of Choe's engagement in Chinese dance activities, now as part of socialist cultural exchange between the PRC and North Korea. ${ }^{119}$

Choe's major impact on the development of Chinese dance began after China's entry into the Korean War, in November of 1950, when Choe returned to Beijing as a war refugee, her school in Pyongyang reportedly having been destroyed by US bombs and two of her students killed. ${ }^{120}$ In Beijing, Choe delivered prominent speeches on Sino-Korean friendship and the urgency of the anti-United States war effort. ${ }^{121}$ At the same time, she returned to her earlier project of researching xiqu dance. Between November 1950 and February 1951, Choe worked with Peking opera actor Mei Lanfang and Kunqu actors Han Shichang and Bai Yunsheng to document and analyze the techniques corresponding to various xiqu role types, including the "virtuous female" (qingyi), "coquettish female" (huadan), and "young scholar" (xiaosheng), as well as for stage properties such as the water sleeve. ${ }^{122}$ During this time, she also began working with a small group of Chinese students and stated publicly her aim to "help facilitate the Chinese people's development of dance art." ${ }^{123}$

The first member of the PRC dance leadership to forcefully promote Choe's work as a future direction for Chinese dance was Chen Jinqing, then vice director of the CAD Dance Ensemble. As mentioned in the introduction, Chen was originally from Shanghai and had been involved in leftist theater during the 1930s. In 1938 she moved to Yanan, where she joined the New Yangge movement. Chen helped lead a major CCP-affiliated dance program at the Northeast Lu Xun Arts Academy (Dongbei Lu 
Xun yishu xueyuan), and in 1948, she traveled from there to Pyongyang to study at Choe's dance research institute. ${ }^{124}$ Chen publicly endorsed Choe in her essay titled "On New Dance Art," which appeared in the same issue of Literary Gazette as Zhong Dianfei's critique of Peace Dove. ${ }^{125}$ After reviewing problems with the post-1949 New Yangge productions, Chen argued that what was needed most to drive China's dance movement forward was higher quality artistic models. Choe, she argued, provided just such a model. Chen identified several of Choe's works as ideal models for Chinese dance creation, including "Breaching Stormy Seas" and "The Woodman and the Maiden." The former, Chen argued, exemplified Choe's masterful approach to dramatic choreography, while the latter offered a useful example of how to adapt folk dance rhythms for the modern stage. In addition to choreography and performance, Chen argued that Choe also had much to offer in the area of dance training. "Choe's set of basic methods and experiences for establishing her native dance basic training program is very worthy of our study," Chen argued, "because we currently need to create our own native dance basic training system." ${ }^{126}$ From Chen's account, learning from Choe appeared the most logical next step for China's dance field.

By January 1951, the Chinese Ministry of Culture had recognized the potential value of Choe's work and invited her to move her dance research institute from Pyongyang to Beijing. ${ }^{127}$ A special training program called the Choe Seung-hui Dance Research Course (Cui Chengxi wudao yanjiu ban) was established at CAD, scheduled to begin in March 1951. ${ }^{128}$ On February 18, the People's Daily published a preview of the content of this course, which doubled as an official endorsement of Choe's guidance of China's dance field, in an article by Choe titled "The Future of Chinese Dance Art." ${ }^{229}$ The article outlined Choe's plan for "helping China's dance world complete the work of organizing Chinese dance" by designing a new movement system derived from xiqu. Drawing on her twenty years of experience studying and creating new dances based on Korean and other Asian dance traditions, Choe wrote, she would apply the same strategies to document and systematize movements from traditional Chinese sources to create China's "new dance art."

One of the important conceptual contributions of Choe's program was a division of traditional sources into two categories: "folk" (minjian) and "classical" (gudian). Rather than indicating the age of a performance practice, these terms indicated differences in social context. In Choe's taxonomy, "folk" referred to dances traditionally performed by peasants. The examples Choe gave in the Korean context were hourglass drum and mask dance, and in the Chinese context yangge, waist drum, and Taiping drum. For Choe, "classical" referred to dances traditionally performed by urban communities or in more formal settings. The examples she gave to illustrate Korean classical dance were sword dance, drum dance, and fan dance, and those for Chinese classical dance were the movements used in Peking opera and Kunqu. While the sources for China's new dance art existed in the movements used in these various folk and classical dance forms, Choe explained, creating new dance art would not mean simply transferring 


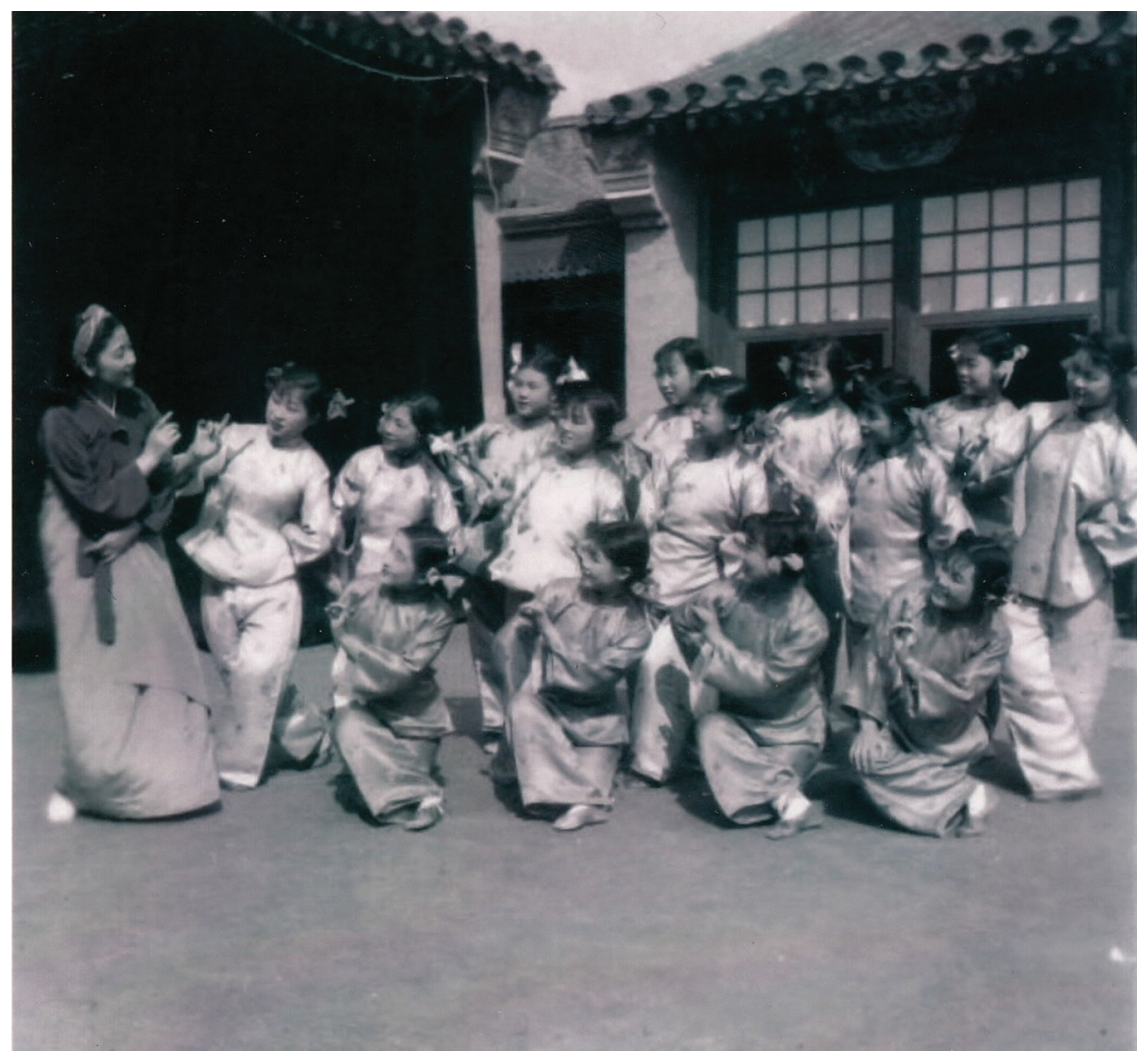

FIGURE 11. Choe Seung-hui and students at the Central Academy of Drama in Beijing, 1952.

Photographer unknown. Reproduced with permission from the private collection of Siqintariha.

these existing movements onto the stage. Rather, as she had learned from her past experience, it would require significant reworking-documenting, analyzing, synthesizing, organizing, systematizing, and creating - to make the movements expressive enough to stand on their own as dance, without the support of lyrics. Echoing Dai's prediction in 1946, Choe warned that this work could not be done by a single person and could not be done quickly_-it would require many people's contributions and would take years to accomplish. Its end result would be an independent, artistically complete dance form that both reflected the realities of Chinas contemporary society and possessed a uniquely Chinese character. ${ }^{130}$

Within a month of the publication of Choe's essay, her plan was already being put into action: a group of young dancers had been recruited from leading ensembles and schools around China and brought to CAD to begin a year of full-time study led by Choe, a course that formally opened on March 17, 1951 (figure 11). ${ }^{131}$ The course was 
given an official quota of 110 students, half from China and half from North Korea. ${ }^{132}$ Students included both men and women, and of the fifty-five Chinese participants, at least sixteen were of non-Han ethnicity. ${ }^{133}$ Although the students were all college-aged (born between 1929 and 1935), they had a wide range of professional backgrounds. Shu Qiao (b. 1933), from Shanghai, had joined the New Fourth Army's New Peace Traveling Ensemble (Xinan lüxingtuan) in 1944, at the age of eleven, and by 1951 was working professionally with the ensemble in Shanghai. ${ }^{134}$ Siqintariha (b. 1932), from Inner Mongolia, started performing professionally in 1947 and had participated in the 1949 All-China Literature and Arts Worker Representative Congress, the 1949 Budapest World Festival of Youth and Students, and the 1950 minority tour as a leading dancer in the Inner Mongolia Cultural Work Troupe. ${ }^{135}$ Meanwhile, Lan Hang (b. 1935), from Beijing, had just been recruited to the CAD Dance Ensemble in 1950, and his first stage experience had been performing in Peace Dove. ${ }^{136}$ Apart from developing a new basic movement system for Chinese dance and creating new dance works on themes related to the Korean War, the course also aimed to prepare these young dancers to serve as dance cadres who could help lead China's new dance field. ${ }^{137}$

Students in the 1951-52 Choe Seung-hui Dance Research Course received studio training in all of Choe's major areas of expertise, including Korean classical and folk dance, Southern dance (nanfang wu), ${ }^{138}$ Soviet ballet and folk dance, New Dance, improvisation, and rhythm, as well as theoretical courses in dance history, political thought, literature, and music. ${ }^{139}$ The focus of the course, however, was on studying and organizing basic movements for Chinese dance derived from xiqu. ${ }^{140}$ During the course's opening ceremonies, where Mei Lanfang personally endorsed Choe's methods, teachers demonstrated the basic movements that would be taught in each dance style. The description for the xiqu section was as follows:

\footnotetext{
Basic movements for Chinese dance organized by Choe Seung-hui. Part one: dance movements of the coquettish female (huadan), young scholar (xiaosheng), virtuous female (qingyi), partnering between virtuous female and young scholar, etc., in Chinese xiqu. These include gait (taibu), horizontal walk (hengbu), diagonal walk (xiebu), brisk steps (suibu), water sleeve (shuixiu), raised sleeve (yangxiu), trembling sleeve (douxiu), spin (xuanzhuan), circling the stage (pao yuanchang), entry and exit (chu ru chang), stalemate (xiangchi), counterpoint (duiwei), eye contact (duikan), falling in love (xiang'ai), expression (biaoqing)—looking, happy, timid, anxious, angry, afraid, crying — and everyday movements (shenghuo dongzuo)—bowing, putting on make-up, opening and closing the door, going up and downstairs, entering and exiting a bridge, boarding and de-boarding a boat, etc. Part two: basic movements of the martial female (wudan), including short spear (huaqiang) — seven kinds of solo spear, nine kinds of dueling spears, and five kinds of double twirling spearsand sword dance-six kinds. ${ }^{141}$
}

This set of techniques embodied what Choe considered to be the "basic movements" of xiqu dance. By training in these movements, she believed, students 


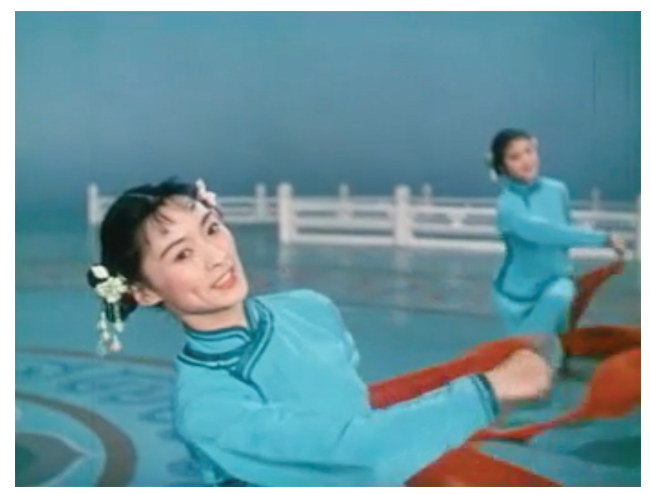

Video 4. "Red Silk Dance," from Colored Butterflies Fluttering About. Beijing Film Studio, 1963.

To watch this video, scan the QR code with your mobile device or visit DOI: https://doi.org/10.1525/luminos.58.4

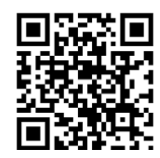

would gain a physical fluency in xiqu movement vocabulary, which they could then use to create their own new Chinese dance choreography. With the advent of xiqu dance, Chinese choreographers would no longer be limited to choosing among the options of yangge, minority dance, vernacular movement, or Western ballet and modern dance to create new works. Rather, they would be able to draw on the local dramatic traditions of Peking opera and Kunqu, using a set of techniques adapted specifically for dancers. ${ }^{142}$

By the spring of 1951, xiqu movement was already appearing in the works of regional ensembles. In the national dance festival held in Beijing that May, South China's Braving Wind and Waves had brought the sounds of xiqu to the dance stage with its use of gong and cymbal percussion. However, the work that really caused a stir was the twelve-person "Red Silk Dance" (Hongchou wu) by Changchun City Cultural Work Troupe (Changchun shi wengongtuan). ${ }^{143}$ "Red Silk Dance" ingeniously showed how xiqu technique could be blended with yangge folk forms to create new dance styles. A version of "Red Silk Dance" recorded on film in 1963 begins with six women dressed in light blue peasant-style jackets and pants bouncing up and down to a yangge rhythm while waving short red scarves in both hands (video 4). A Chinese folk ensemble accompanies the dancers with a string melody set to gong and cymbal beats and a suona (Chinese clarinet), evoking the sounds of a rural festival. Then, six male dancers bound onto the stage in white costumes and head towels, holding sticks with tufts of red fabric on top. With a leap, the men thrust their arms up, and the tufts explode into red silk streamers about four meters long, painting the air in unison looping, swirling red patterns. Finally, the women return with long silks too, and the dancing carries on in a play of melodies, shapes, and stage arrangements. ${ }^{144}$ 
A major innovation of "Red Silk Dance" was that it melded the silk streamer technique used in xiqu with the bouncing footwork and playfulness of yangge and other folk forms. According to the work's creators, they had spent a year studying and experimenting with the techniques of three different types of traditional performers: yangge dancers, errenzhuan (a type of northeastern bawdy song and dance duet, also called bengbengxi) performers, and Peking opera actors. The end result was a work that, in their words, "extricated [silk dance] from Peking opera and made it into an independent dance form that, through revision, expresses new content." ${ }^{145}$ The silk techniques used in "Red Silk Dance," although commonly perceived today as a fundamental component of Chinese folk dance, were in fact an innovation introduced in 1951 through the popularization of xiqu dance and its experimental blending with New Yangge and other folk forms. After its premiere, ensembles around China clamored to learn the new silk technique. To meet demand, a manual was published in 1953 that provided detailed diagrams and step-by-step instructions. ${ }^{146}$ The bulk of the book's technical content was spent explaining how to manipulate the silk streamers. Readers were guided not only on how to construct the streamers but also on how to hold them, how to apply the correct amount of force to provide lift without causing exhaustion to the dancer, and, most importantly, how to achieve the effects of the various shapes and patterns. The book outlined nineteen "basic movements" of silk dance technique, from the simple "small figure eight" to the complex "double figure eight cross circle." 147 Such manuals were one of the ways that xiqu dance, following New Yangge and Frontier Dance, became popularized.

Choe Seung-hui returned to North Korea in October of $1952 .{ }^{148}$ However, the nearly two years she spent in the early PRC between 1950 and 1952 left a strong impact on the later development of Chinese dance. As Dai Ailian commented in 1951, "Choe Seung-hui has already sown her dance art seeds, which will continue to grow and blossom on Chinese soil." ${ }^{149}$ Between May 25 and June 15, 1952, the Choe Seung-hui Dance Research Course gave its graduation performances in Beijing, which included thirty-two shows seen by over twenty thousand people. ${ }^{150}$ One of the most obvious continuities between Choe's work in the CAD program and developments in Chinese dance after her departure was the long-lasting and widespread practice of using xiqu movement as basic training for Chinese dancers. One of China's most important national dance ensembles-the Central Experimental Opera Theater (Zhongyang shiyan gejuyuan), established in Beijing in 1953-would develop xiqu dance by the late 1950 into the basis for a new form of full-length narrative Chinese dance choreography, as discussed in the next chapter. The first arena in which Choe's work would have a significant impact, however, was in China's dance schools. 


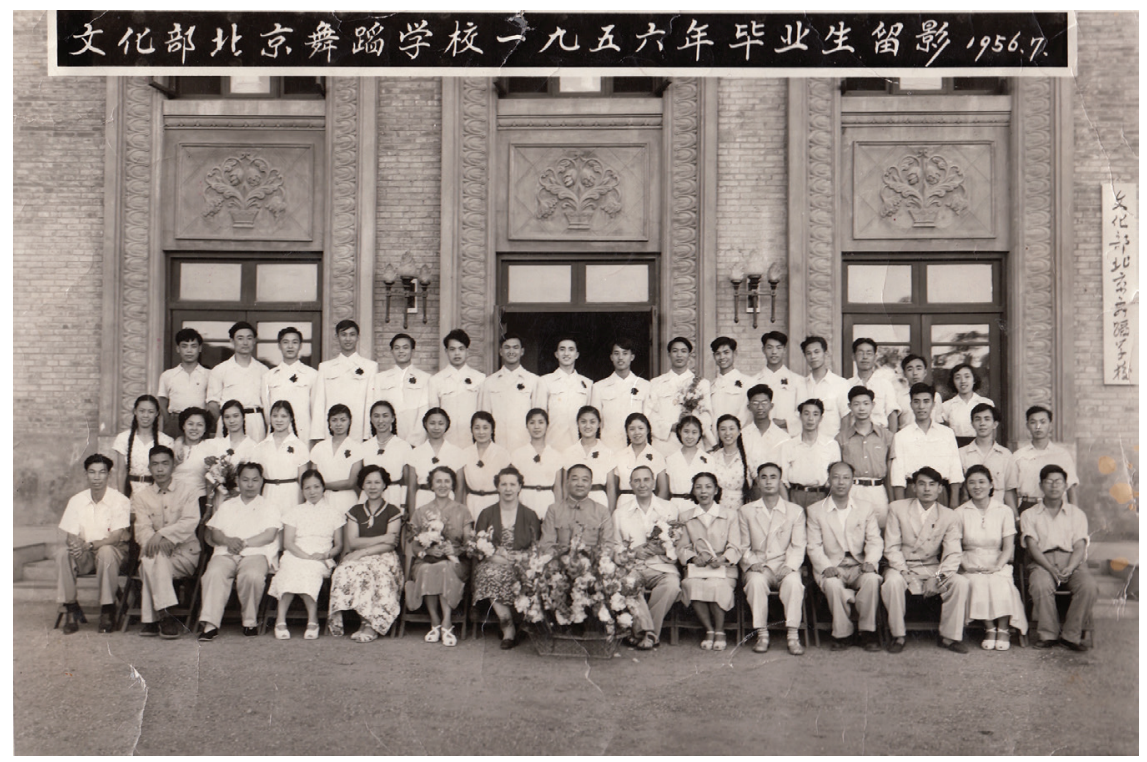

FIGURE 12. Beijing Dance School graduates and teachers, 1956. Photographer unknown. Reproduced with permission from the private collection of Siqintariha.

\section{CONCLUSION: A NATIONAL CURRICULUM}

The formal experiments of the early 1950 occurred in many varieties, from daring stage productions to innovative classroom approaches. They occurred in the capital and in the provinces, driven by artists from the center, the border, and beyond. Events like national festivals and the formation of national ensembles suggested that Chinese dance was coming together as a coherent and recognizable artistic medium. However, the most outstanding expression of this development was the creation of a national training curriculum. Training is fundamental to the production of a dance form, because it is through this process that bodies attain the habits and skills that transform them into dance mediums. By creating a national curriculum, the dance community established a standard that determined what this medium would be-one that extended beyond any single ensemble, choreographer, region, style, or production. It determined what was to become understood as Chinese dance in a strictly formal sense, as defined by a set of fundamental movements and techniques.

The institution in which this curriculum was first worked out and put into practice was the Beijing Dance School (Beijing wudao xuexiao), which opened formally on September 6, 1954 (figure 12). ${ }^{151}$ The school was designed to offer a live-in sixyear vocational education for students beginning at or under the age of twelve, taking the place of middle and high school. ${ }^{152}$ In the 1954 recruitment cycle, in order to fill all levels of the curriculum, the school only recruited new students for the 
first-year program. It filled the remaining second- through sixth-year slots with individuals already working as professional dancers in ensembles around China. ${ }^{153}$ In its first year, the school enrolled a total of 198 students and offered studio training in two major dance styles: Chinese and European. The Chinese dance program offered courses in xiqu-based Chinese classical dance and four styles of Chinese folk dance, including Han, Korean, Tibetan, and Uyghur. ${ }^{154}$ The European dance program offered courses in ballet (conceived of as "European classical dance") and European folk dance (also known as "European character dance"), including Russian, Spanish, Hungarian, and Polish. ${ }^{155}$ Over the next few years, the student body expanded and diversified, and courses in additional styles were added. By 1956, the school had a total of 328 students, including ten exchange students from the Democratic Republic of Vietnam and twenty-four advanced students from China's regional dance ensembles enrolled in a short-term program in dance drama choreography led by a Soviet instructor, Viktor Ivanovich Tsaplin (1903-1968). ${ }^{156}$ In 1957 a new major in South and Southeast Asian dance, known as Oriental Dance (Dongfang wu), was launched, led by four Balinese dance experts from Indonesia. ${ }^{157}$ From 1954 to 1966, the breakdown of total graduates in each major was as follows: Chinese dance-39o; European dance/ballet-156; choreography-39; Oriental Dance- $33 .{ }^{158}$ Thus, throughout the pre-Cultural Revolution period, Chinese dance remained the focus of the school's training mission.

The Ministry of Culture, which oversaw the founding of the school, recruited area experts to direct all aspects of the school's operations, including administration, teacher training, management of teaching and research, and student recruitment. Dai Ailian and Chen Jinqing, who were then leading the Central Song and Dance Ensemble, were appointed to serve as the school's first director and vice director, respectively. For teacher training, an intensive program took place between February and July 1954 that prepared over forty teachers. ${ }^{159}$ During this program, different experts were recruited to provide training in each dance style: Peking opera and Kunqu specialists Gao Lianjia, Li Chenglian, Hou Yongkui (1911-1981), and Ma Xianglin (1913-1994) led teacher training for Chinese classical dance; ${ }^{160}$ Anhui flower drum lantern specialist Feng Guopei (1914-2012) and Hebei yangge specialist Zhou Guobao led teacher training in Han folk dance; Korean dance specialists Zhao Dexian (1913-2002) and Piao Rongyuan (1930-1992), Tibetan guozhuang specialist Suona Zhaxi, and Uyghur dance specialist Qemberxanim led teacher training in Korean, Tibetan, and Uyghur folk dance, respectively; ${ }^{161}$ and Soviet ballet specialist Ol'ga Il'ina, from the Moscow Choreographic Institute, led teacher training in ballet and European character dance. ${ }^{162}$ During the school's first semester, leading members of the Chinese dance field Ye Ning, Peng Song, and Sheng Jie were appointed to manage teaching and research in the Chinese dance program. ${ }^{163}$ Yuan Shuihai and $\mathrm{Lu}$ Wenjian were appointed to oversee the ballet curriculum. ${ }^{164}$ Student recruitment was jointly administered by Chen Jinqing and Ol'ga Il'ina. ${ }^{165}$ 
The Beijing Dance School's Chinese dance curriculum skillfully united what were now the three established streams of Chinese dance-Han folk dance (inherited from New Yangge), minority dance (inherited from Frontier Dance), and xiqu dance (inherited from Choe's program). ${ }^{166}$ The strong impact of all three dance styles within the new curriculum was immediately clear in the school's first yearend performance, held in May of $1955 .{ }^{167}$ The production's finale was a work called "Marriage" (Jiehun), composed in the vocabulary of Northeast-style yangge. ${ }^{168}$ Its costuming was clearly inspired by New Yangge stage aesthetics, with the groom in overalls, the bride in an embroidered jacket, and the group dancers using handkerchiefs and wearing white head towels. ${ }^{169}$ Four works of minority dance were spread throughout the program. They included a Korean-themed dance called "Bright" (Minglang), a Uyghur-themed dance called "Holiday Cheer" (Jieri de huanle), a Tibetan-themed dance called "Friendship" (Youyi), and a Mongol-themed dance called "Ordos" (E'erduosi). ${ }^{170}$ Costumes used in these pieces resembled those worn in the 1949 All-China Literature and Arts Worker Representative Congress Frontier Folk Dance Introduction Plenary and the 1950 minority tour. ${ }^{171}$ Finally, the production contained four Chinese classical dance works inspired by xiqu: "Picking Flowers" (Cai hua), choreographed by Kunqu actor Ma Xianglin; "Young Patriot" (Shaonian aiguozhe) and "Shepard Flute" (Mu di), both choreographed by Peking opera actor Li Chenglian; and "Interrupted Dream" (Jing meng), based on a segment from the famous Kunqu drama Peony Pavilion. ${ }^{172}$ "Picking Flowers" and "Interrupted Dream" were both performed by students of Choe Seung-hui, and with the exception of "Young Patriot," which followed an aesthetic more akin to spoken drama, costumes for the other Chinese classical dance works resembled designs used in xiqu and regional drama. ${ }^{173}$ Of the ten Chinese dance works, eight used musical accompaniment provided by a Chinese-style orchestra, following the norm for Chinese dance practice as developed through Braving Wind and Waves, the 1950 minority tour, and successful newer works such as "Red Silk Dance." ${ }_{174}$

As China's only national-level professional conservatory dedicated solely to dance, the Beijing Dance School had an important impact on standardizing and disseminating Chinese dance and its pedagogical methods across the country. The cohort of 1955 graduates were assigned jobs in at least seven locations-including Beijing, Shanghai, Guangdong, Guangxi, Sichuan, Shaanxi, Yunnan, and Jilinand by 1960, the school's graduates were working in every province and autonomous region across China with the exception of Hebei and Liaoning. ${ }^{175}$ Over time, as more students graduated from the school and these students went on to train students of their own in diverse locales across the country, the Beijing Dance School's program gained the status of a national dance curriculum. By 1956 the school had the nickname Cradle of Dancers, indicating that it was China's leading center for dance education. ${ }^{176}$ In 1960, when the school published its first edition 
of Teaching Method for Chinese Classical Dance, the print run was 4,500 copies, indicating a plan for widespread use. ${ }^{177}$

Although the school taught multiple dance styles during the 1950s, it was the Chinese dance program that had the greatest impact on China's dance development during this period. Until December 31, 1959, when the Beijing Dance Academy's Attached Experimental Ballet Ensemble was established, all professional music and dance ensembles in China-of which there were dozens across the country by early 1957 -specialized in Chinese dance. ${ }^{178}$ For this reason, other dance styles had little direct relevance to most dancers' professional work. While ballet was typically seen as a useful form of physical training for dancers during this era, it was not regarded as an important medium for new choreography. After the failure of Peace Dove, the next new work based in ballet movement vocabulary did not appear until 1959. Another reason that Chinese dance had the most impact during this period was that the first cohorts of students majoring in non-Chinese styles did not start to matriculate until around 1958, with the first cohort of ballet majors graduating in 1959 and the first cohort of Oriental Dance majors in 1960. ${ }^{179}$ Rather than being assigned to other locales, ballet majors were almost all retained either to teach at the school or to join the school's new Experimental Ballet Ensemble (Shiyan baleiwuju tuan), founded in late $1959 .{ }^{180}$ Graduates of the school's Oriental Dance program were similarly kept in Beijing first to teach and then to form the new Oriental Song and Dance Ensemble (Dongfang gewutuan), established in early $1962 .{ }^{181}$ Thus, while the ballet and Oriental Dance curricula initially trained dancers for a limited set of jobs in institutions found only in Beijing, the Chinese dance curriculum trained dancers for ensembles located all over the country. By the mid-1950s, it was possible to say not only that Chinese dance had been created, but that it had truly become China's national dance form. 